\title{
Correction to: Selective Laser Melting Process for Sensor Embedding into SUS316L with Heat Dissipative Inner Cavity Design
}

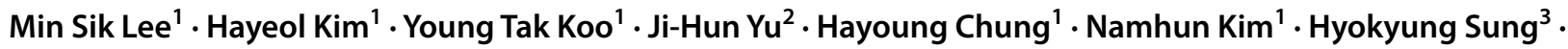 \\ Im Doo Jung ${ }^{1}$
}

Published online: 8 December 2021

(c) The Korean Institute of Metals and Materials 2021

\section{Correction to: Metals and Materials International https://doi.org/10.1007/s12540-021-01106-3}

In the original publication of the article, the equally contribution statement was missed. The authors Min Sik Lee and Hayeol Kim should have been denoted as equally contributing authors.

The original article has been corrected.

Publisher's Note Springer Nature remains neutral with regard to jurisdictional claims in published maps and institutional affiliations.

The original article can be found online at https://doi.org/10.1007/ s12540-021-01106-3.

Hyokyung Sung

hksung@gnu.ac.kr

$\bowtie$ Im Doo Jung

idjung@unist.ac.kr

1 Department of Mechanical Engineering, Ulsan National Institute of Science and Technology, 44919 Ulsan,

Republic of Korea

2 Korea Institute of Materials Science, 51508 Changwon, Republic of Korea

3 Department of Materials Engineering and Convergence Technology, Gyeongsang National University (GNU), Jinju 52828, Republic of Korea 